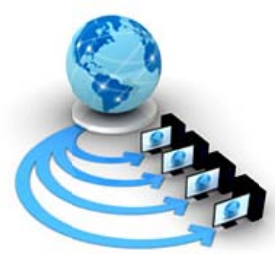

Volume 9, No. 1, January-February 2018

ISSN No. 0976-5697

International Journal of Advanced Research in Computer Science

RESEARCH PAPER

\title{
EARTHQUAKE EARLY WARNING SYSTEM IN THE WESTERN HIMALAYAN REGION OF INDIA: AN ARCHITECTURAL DESIGN USING THE BotRf SIMULATION TOOL
}

\author{
Dhirendra Sharma \\ University Institute of Information Technology, \\ Himachal Pradesh University, \\ Shimla 171005, India
}

\author{
Marco Zennaro \\ ICT for Development Laboratory, \\ The Abdus Salam International Centre of Theoretical \\ Physics, StradaCostiera 11 34014, Trieste, Italy
}

\author{
Ermanno Pietrosemoli \\ ICT for Development Laboratory, \\ The Abdus Salam International Centre of Theoretical Physics, \\ StradaCostiera 11 34014, Trieste, Italy
}

\begin{abstract}
We present a Long distance Wi-Fi based architectural design for an early earthquake warning system using the BotRf Telegram simulation tool for wireless links design. In this paper, a dedicated bidirectional communication ring connecting three locations within Himachal Pradesh state with a ring topology is proposed. This topology allows for redundancy to transport the signal to the earthquake monitoring centres by two independent routes, a direct one and another using an intermediate site as a repeater point. Being a dedicated ring, not part of the commercial Internet, it is not affected by commercial traffic during and after an earthquake. Even in case of disrupted service of the existing commercial communications networks, as often happens after a seismic event, the proposed network would still operate since it will be autonomously powered by means of solar panels and batteries. Therefore, the seismic data will be delivered to the emergency offices that can effectively react with the proper measures. The functional architectural design testbed for early earthquake warning (EEW) system would be available in the western Himalayan Region of India constituting a major step to improve earthquake monitoring alertness in this region.
\end{abstract}

Keywords: Early Earthquake Warning System (EEWS), Long distance WiFi, BotRf, Radio link simulation, Line of Sight (LOS)

\section{INTRODUCTION}

In the era of advancement in Science and Technology, it is still a big challenge to have a forewarning about the earthquake.Natural Disaster due to earthquake is a major concern of all human beings around the globe. A few geographic locations in Himachal in the western Himalayan region of India are under Seismic zone V, considerably vulnerable to earthquakes.

It was a harsh truth to witness 25th April 2015 Nepal earthquake (also known as the Gorkha earthquake) with a magnitude of $7.8 \mathrm{M}$ at about a distance of $80 \mathrm{~km}$ to the northwest of Kathmandu, the capital of Nepal, in the Himalayan Region, which killed more than 9,000 people and injured more than 25,000 [1]. Its epicentre was east of the district of Lamjung and its hypocentre was at a depth of approximately $15 \mathrm{~km}$. This earthquake created great panic and people were hesitant to stay in their homes. It was the worst natural disaster to strike Nepal since the 1934 Nepal-Bihar earthquake. Earlier, the western Himalayan Region of India faced another, still worse, earthquake in Kangra district in the state of Himachal Pradesh, on $4^{\text {th }}$ April 1905 , with a magnitude $7.8 \mathrm{M}$, which killed more than 20,000 people and caused terrible destruction of buildings in the cities of Kangra, Mcleodganj, Dharamshala and Palampur [2].The devastation caused is shown in Figure 1.

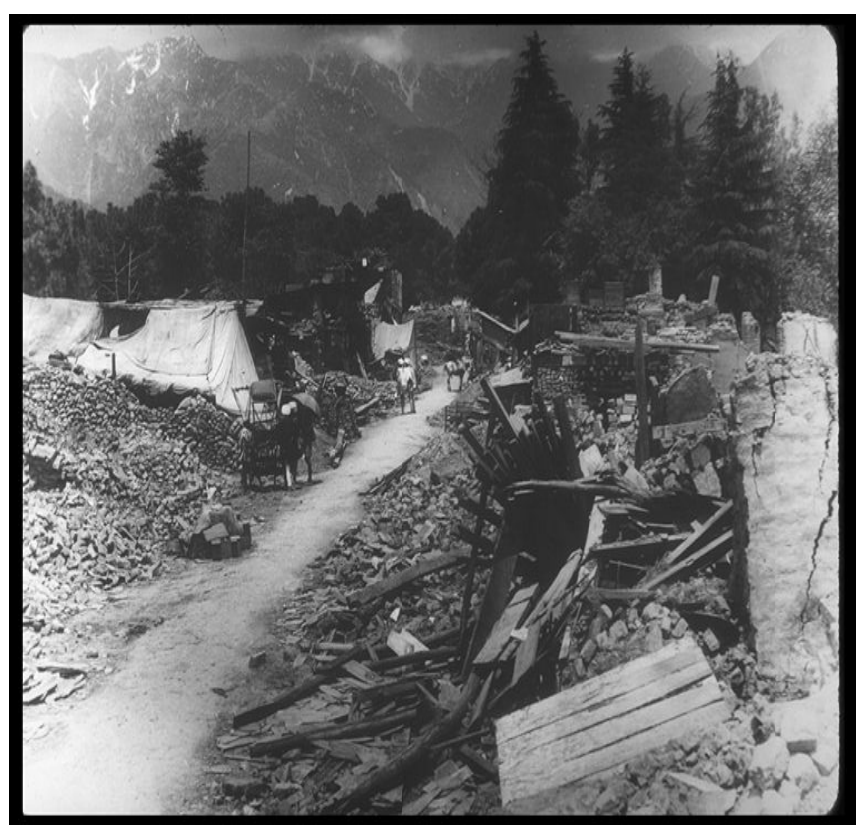

Figure 1. Market after earthquake in Palampur (Kangra Distt.), India.

The Nepal earthquake also triggered an avalanche on Mount Everest making April 25, 2015 the deadliest day killing at least 19 people. It further triggered another huge avalanche in the Langtang valley, where 250 people were reported missing. In the past, there 
had been many other instances of earthquakes in India, with many lives lost. These tremors were also felt throughout India, from north to down south in Kerala; Bhutan, Bangladesh and Pakistan [3], details given below:

\section{MAJOR EARTHQUAKES IN INDIA}

\begin{tabular}{|c|c|c|c|}
\hline OATE & LOCATION & FATALITIES & MAONTUDDE \\
\hline Sept 18,1737 & Kolkata & $1,00,000$ & NA \\
\hline June 16,1819 & Kutch District & $>1,543$ & $7.7-8.2$ \\
\hline \multirow[t]{2}{*}{ Dec 31,1881} & Ândam an and & none & 7.9 \\
\hline & Nicobar Islands & & \\
\hline June 12,1897 & Shillong Plateau & 1,500 & 8.1 \\
\hline April 4,1905 & Kangra (HP) & 20,000 & 8.25 \\
\hline Jan 15,1934 & Bihar & 8,100 & 8.7 \\
\hline Aug 15,1950 & $\begin{array}{l}\text { Arunachal Pradesh } \\
\text { China border }\end{array}$ & 1,526 & 8.5 \\
\hline $\operatorname{Jan} 19,1975$ & Himachal Pradesh & 47 & 6.8 \\
\hline Odt 20,1991 & Uttarkashi & 32,000 & 7.0 \\
\hline Sep 30,1993 & Latur-Killari & 9,748 & 6.2 \\
\hline Jan 26, 2001 & Kutchin & 20,000 & $7.6 \pi 7$ \\
\hline Dec 26,2004 & $\begin{array}{l}\text { Off west coast, } \\
\text { northern Sum atra, } \\
\text { India, Sri Lanka, Maldives }\end{array}$ & $2,83,106$ & 9.0109 .3 \\
\hline 0 d 8,2005 & Kashmir, HP, Pakistan & $>80,000$ & 7.6 \\
\hline Sept 7,2011 & Delhi & To be determined & 4.2 \\
\hline Sept 18,2011 & Sikkim & To be determined & 6.9 \\
\hline Marrh 5 201? & New fiplhi & In he efetermined & 49 \\
\hline
\end{tabular}

Human Life is extremely precious, which demands an efficient \& prompt Early Earthquake Warning Systems (EEWS) in each of the highly sensitive seismic zones with minimum delay. Thismotivated the present study aimed at building areliable early warning infrastructure at long distances. If high-intensity earthquake hits Himachal Pradesh state, it might disrupt the traditional communications lines and road, bridges and cables might be washed away. In this scenario, the only source of communications would be dedicated radio links, since mobile phone, internet and other cabled media may not work, according to [4].

Traditionally, Wireless Sensor Networks(WSN)have beensuccessful deployed indoor for distances upto 30 metres, and outdoors setting up to a couple of kilometres. Nevertheless, using high gain antennas and modified protocolos very long distances and high throughput can be achieved with modified WiFi low cost equipment.The longest WiFi link on recordwas established by Ermanno Pietrosemoli(one of the author of this paper) over a $382 \mathrm{~km}$ path in 2006 [5], [6].By cascading several links in a row the Rural Telecommunication Research Group of Pontificia Universidad Catolica del Peru (GTR PUCP) in collaboration with the Spanish EHAS Foundation,was able to span $445 \mathrm{~km}$ in the Amazonian jungle [7] to service rural communities along the Napo river. However, as far as we know, this kind of long distance communication has not been utilized for early earthquake warning and monitoring systems.

In this paper, an effort has been made to design an EEWS as a pilot project for the western Himalayan Region of Indiausing long distance WiFi links. This would be helpful for sending an early alert triggered by sensors when seismic waves are generated by an earthquake. Such an advance warning system could allow people to take appropriate actions to protect their lives.

A demonstration EEW System [8] called ShakeAlert began sending test notifications to selected users in California in January 2012. The system detects earthquakes using the California Integrated Seismic Network (CISN), an existing network of about 400 high-quality ground motion sensors. CISN is a partnership between the United States Geological Survey (USGS), State of California, Caltech, and University of California at Berkeley, and is one of the seven regional networks that make up the Advanced National Seismic System (ANSS).

ShakeAlert is transitioning from the current demonstration system to a production prototype for the West Coast. The USGS has published an Implementation Plan with the steps needed to complete the system and begin issuing public alerts. The basics are schematically presented in Fig.2.

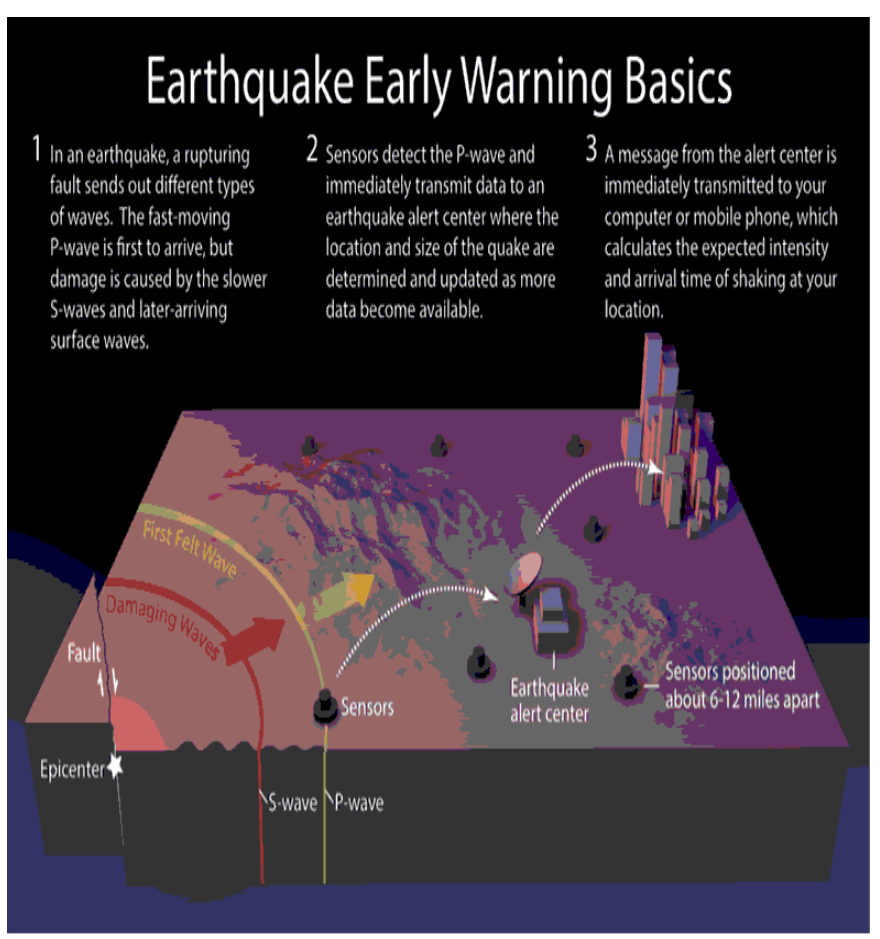

Figure 2.

In figure 2, the $\mathrm{P}$ is the longitudinal pressure wave quite deep inside the earth and the $S$ wave is the transverse body wave responsible for destruction 
on the surface of the earth. Propagation velocity ratio of these two waves is roughly 2:1.

Earthquake early warning systems, like ShakeAlert, work because the warning message can be transmitted almost instantaneously, whereas the shaking waves from the earthquake travel through the shallow layers of the Earth at speeds of about one to a few kilometers per second ( 0.5 to 3 miles per second) [10]. This diagram shows how the system would function. When an earthquake occurs, both compressional (P) waves and transverse (S) waves radiate outward from the epicenter. The $\mathrm{P}$ wave, which travels fastest, trips sensors placed in the landscape, causing alert signals to be sent ahead, giving people and automated electronic systems some time (seconds to minutes) to take precautionary actions before damage can begin with the arrival of the slower but stronger $\mathrm{S}$ waves and later-arriving surface waves. Computers and mobile phones receiving the alert message would be able to calculate the expected arrival time and intensity of shaking at your location if time permits. Main idea behind is to provide an early alarm system so that people can go out of buildings and save their life.

\section{METHODOLOGY:}

\subsection{The methodology consists of the following steps:}

- Identification of sites in the highly sensitive seismic zone (V): For this pilot, three sites weretargeted namely Dharamshala (H.P.), Kufri (Shimla) and Kasuali. These sites fall within the province of Himachal Pradesh, India. It is pertinent to the mention that Shimla (capital of Himachal Pradesh) and Dharamshala (second winter capital of the state of Himachal Pradesh) have been identified as Smart Cities by the Government of India. Therefore, it is expected that funds would be available for innovative ideas/projects in them. The coordinates of the sites are given in table I.

Table-1: Sites for Radio Links

\begin{tabular}{|c|c|c|c|}
\hline Site Name & $\begin{array}{c}\text { Latitude } \\
\text { Longitude }\end{array}$ & $\begin{array}{c}\text { Antenna } \\
\text { Height }\end{array}$ & Altitude \\
\hline $\begin{array}{c}\text { Dharamshala } \\
\text { (DS) }\end{array}$ & $\begin{array}{c}32.287100 \\
76.393886\end{array}$ & $3 \mathrm{~m}$ & $4531 \mathrm{~m}$ \\
\hline Kufri & $\begin{array}{c}31.096454 \\
77.262646\end{array}$ & $3 \mathrm{~m}$ & $2675 \mathrm{~m}$ \\
\hline Kasauli & 30.901792 & $3 \mathrm{~m}$ & $1841 \mathrm{~m}$ \\
& 76.961881 & & \\
\hline
\end{tabular}

- Setting up of Earthquake Monitoring Station (EMS): Seismic sensors installed in vulnerable areas will convey data by means of a dedicated wireless sensor network (WSN). Earthquake Monitoring Station would be installed at Dharamshala and Shimla. Kasauli will act as a relay centre for redundancy thus providing added reliability.

- Communication of earthquake event: As soon as the $\mathrm{P}$ wave is detected by the seismic sensor this information is transferred to the earthquake monitoring station (EMS)in less than $1 \mathrm{~ms}$, the time it takes for the radio waveto travel $300 \mathrm{~km}$. When the servers at EMS receive the warning, they set up an alarm system without human intervention. This alarm will be spread by different media to all interested parties.

- Warning Signal: A high volume siren will also be actuated. (During the mock drill the purpose of the siren will be explained). Efforts will be made to sign a memorandum of understanding (MOU) with all operators and the Government of Himachal Pradesh, to make it possible that every mobile phone in the area will receive an earthquake alert.The purpose of using a long distance modified WiFi is to have an independent, low latency transmission system which is reliable, robust and remotely managed. This allows to launch an early warning system that can contribute to the safety human lives.

\subsection{Radio Links planning using the BotRfTelegramtool.}

The first condition for a successful radio link at microwave frequencies is that there should be a clear line of sight (LOS) without any obstructions that could penetrate in the Fresnel zone, the volume around the LOS occupied by the radio wave. The second condition is that the received signal power should be strong enough for correct recodification. The establishment of the first condition requires a complete knowledge of the topography of the intervening terrain and the propagation path of the wave. This information is used to calculate the power expected at the receiver station. BotRf isa free, open source and user friendly bot based on the Telegram messaging application that can be used for the simulation and design of wireless links [8]. Telegram [9] is a cloud-based instant messaging service, similar to Whatsapp. Itcan beused in smartphones (Android, iOS, Windows Phone, Ubuntu Touch) or run as an operating system independent web browser application.Telegram can be used without a phone once the account is established. The client is free and has no limits on the size of media that can be 
exchanged. Servers are distributed in many locations around the world.

Giving the calc command with the names and coordinates of the extreme to BotRfwill result in a profile of the intervening terrain and a graph of of the radio wave propagating above it at the chosen frequency. The program will warn of any obstacle that intrudes in the Fresnel zone.To calculate the received power strength the radio and antenna parameters must also be entered. For our design we chose the following values:

\section{Operating frequency: $5.8 \mathrm{GHz}$}

\section{Transmision Power: 20 dBm}

\section{Receiver Sensitivity: $-\mathbf{8 0} \mathrm{dBm}$}

Antenna Gain: 34 dBi (same antenna used for transmission and reception)

For example, to simulate the link from Dharamshala to Kufri using BotRf we entered: calc ds kufri

Results

\section{Free space path loss: $151.59 \mathrm{~dB}$}

No obstructions to LOS path due to terrain were detected.

Then figure 3(a) was displayed. In it one can see the apparent trajectory of the radio wave and the first Fresnel zone in magenta, the profile of the terrain in green and the apparent earth curvature in brown. We say apparent because the radio wave in reality follows a curve, but by modifying the radio of curvature of the earth according with the atmospheric refraction index we can depict the radio trajectory as a straight line. Its apparent that no obstacle intrude in the Fresnel zone over this $156 \mathrm{~km}$ path.

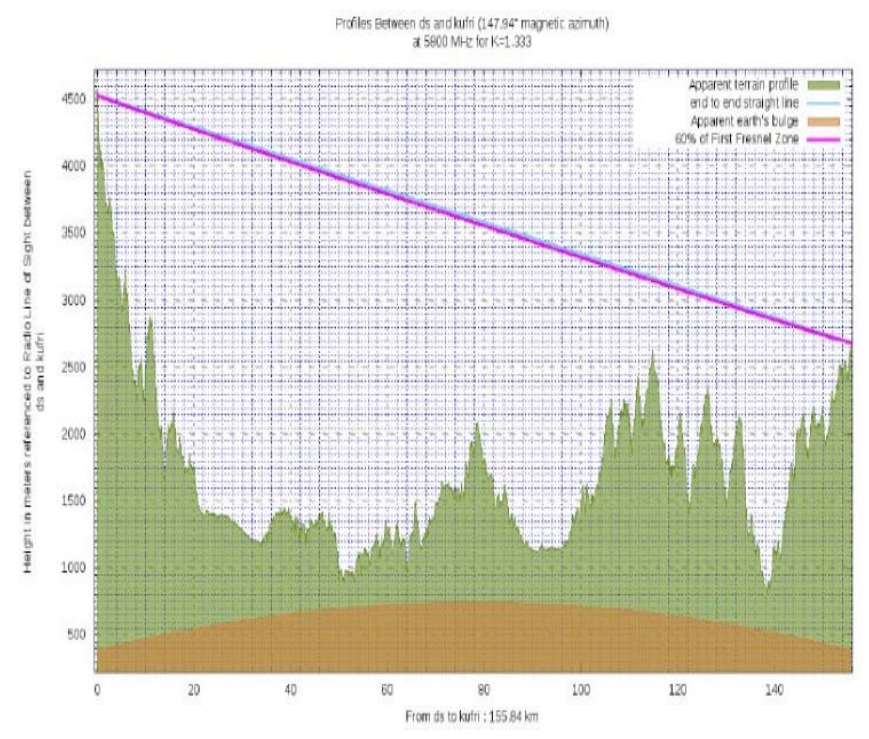

Figure 3 (a)Dharamshala (DS) to Kufri

To calculate the margin of the received signal above the receiver sensitivity we use the command:

pow Sitel Site2 TxPw TxCl TxAg RxAg RxCl

$\mathrm{RxSe}$

where:

TxPw: transmitter power $(\mathrm{dBm})$

$\mathrm{TxCl}$ : transmitter cable loss (dB)

TxAg: transmitter Antenna gain ( $\mathrm{dBi})$

$\mathrm{RxAg:}$ receiver Antenna gain ( $\mathrm{dBi})$

$\mathrm{RxCl}$ : receiver cable loss $(\mathrm{dB})$

RxSe: Receiver sensitivity

\section{BotRf}

pow ds kufri $200.034 .034 .00 .0-80.0$

Obtaining Figure 3 (b):

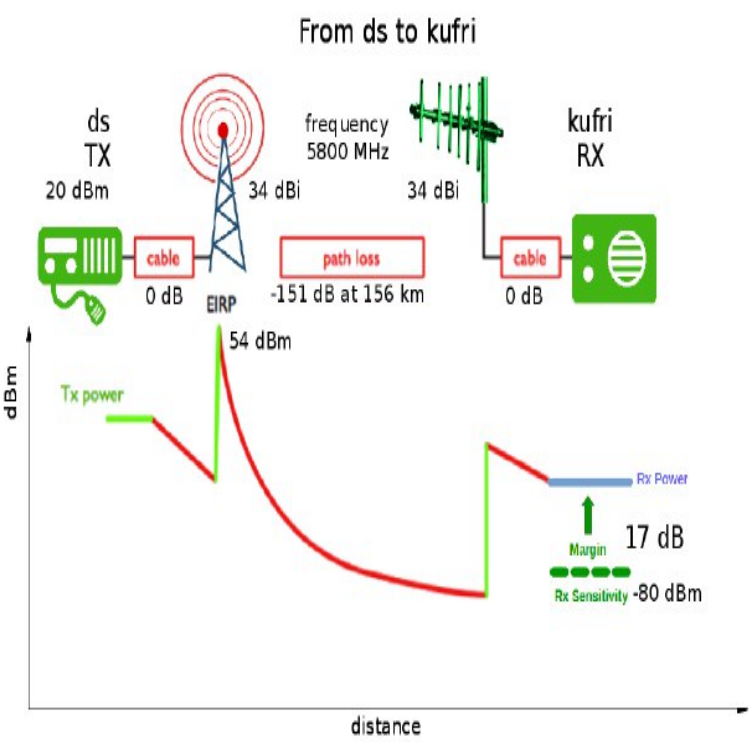

Figure 3 (b) Power vs distance on the Ds-Kufri link 
In this diagram we can see that at the frequency of $5800 \mathrm{MHz}$ the received signal will have a margin of $17 \mathrm{~dB}$ above the receiver sensitivity of $-80 \mathrm{dBm}$. This means that the received signal has a value of $-63 \mathrm{dBm}$ after traversing the $156 \mathrm{~km}$ that separate Dharamsala from Kufri.

Further details of the link can be obtained using the $r$ command:

\section{BotRf}

$r$ ds kufri

Results

Path Analysis from ds to kufri

Distance between ds and kufri: $155.84 \mathrm{~km}$

Transmitter site: ds

Site location: $(+32.2871,+76.3939)(+32$

$17^{\prime} 13^{\prime \prime} /+76$ 23'37")

Elevation: $4531 \mathrm{~m}$ above sea level

Antenna height: $3 \mathrm{~m}$ above ground / $4534 \mathrm{~m}$

above sea level

Azimuth to kufri: 147.94 degrees

Depression angle to kufri: -1.2049 degrees

Receiver site: kufri

Site location: $(+31.0965,+77.2626)(+31$

$5^{\prime} 47^{\prime \prime} /+77$ 15'45")

Elevation: $2675 \mathrm{~m}$ above sea level

Antenna height: $3 \mathrm{~m}$ above ground / $2678 \mathrm{~m}$

above sea level

Azimuth to ds: 328.39 degrees

Elevation angle to ds: +0.1543 degrees

Elevation angle to the first obstruction: +0.1548

degrees

Analysis model: Longley-Rice

Parameters used in this analysis:

Earth's Dielectric Constant: 15.000

Earth's Conductivity: 0.005 Siemens/meter

Atmospheric Bending Constant (N-units): 301.000

ppm

Frequency: $5800 \mathrm{MHz}$

Radio Climate: 5 (Continental Temperate)

Polarization: 0 (Horizontal)

Fraction of Situations: $50.0 \%$

Fraction of Time: $50.0 \%$

Summary for the link between ds and kufri:

Free space path loss: $151.59 \mathrm{~dB}$

Longley-Rice path loss: $151.41 \mathrm{~dB}$

Attenuation due to terrain shielding: $-0.18 \mathrm{~dB}$
Mode of propagation: Line-Of-Sight Mode

Longley-Rice model error code: 0

ErrorMessage[0]:

"No error"

No obstructions to LOS path due to terrain were detected.

Following the same procedure we obtained Figure 3(c) for the link from Dharamsala to Kasauli:

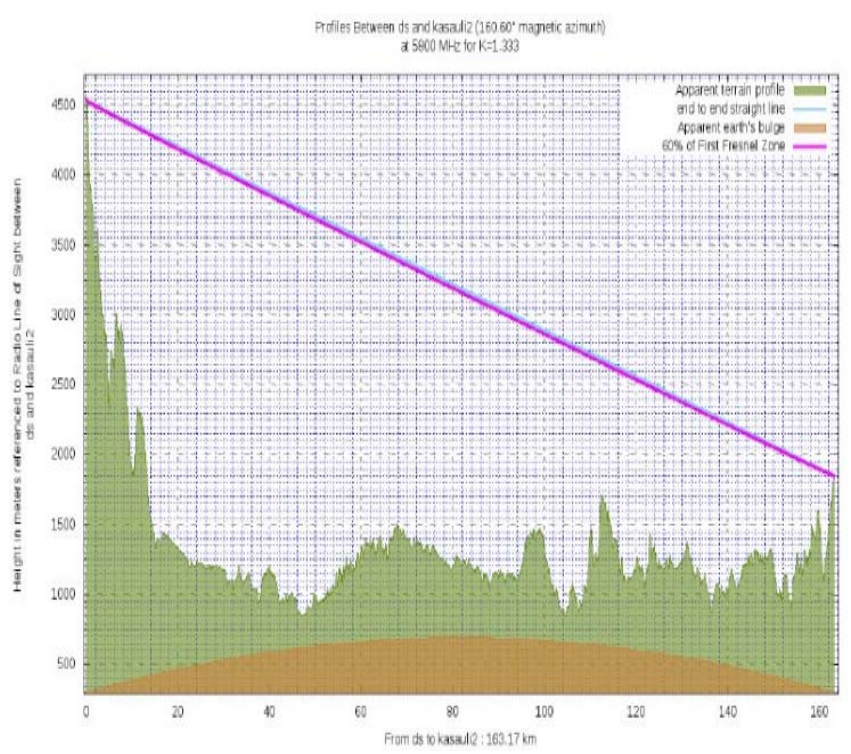

Figure 3 (c)Link 2- Dharamshala to Kasauli

Again, there are no obstales in this trajectory.

Using the pow command we get Figure 3 (d):

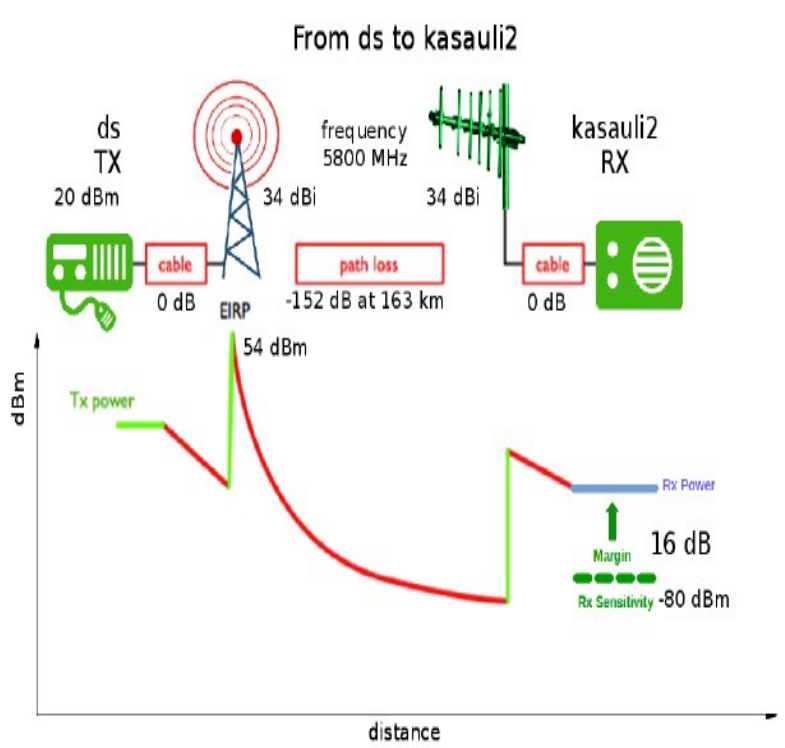

Figure 3 (d)Power vs distance on the DS and Kasauli link. 
Which shows that the margin is very similar since there are no obstructions and the path loss is similar. The third link between Kufri and Shimla is shown in Figure 3 (e), again no obstructions encountered, but the margin, depicted in Figure 3(f) is now $29 \mathrm{~dB}$ since the distance is only $36 \mathrm{~km}$.

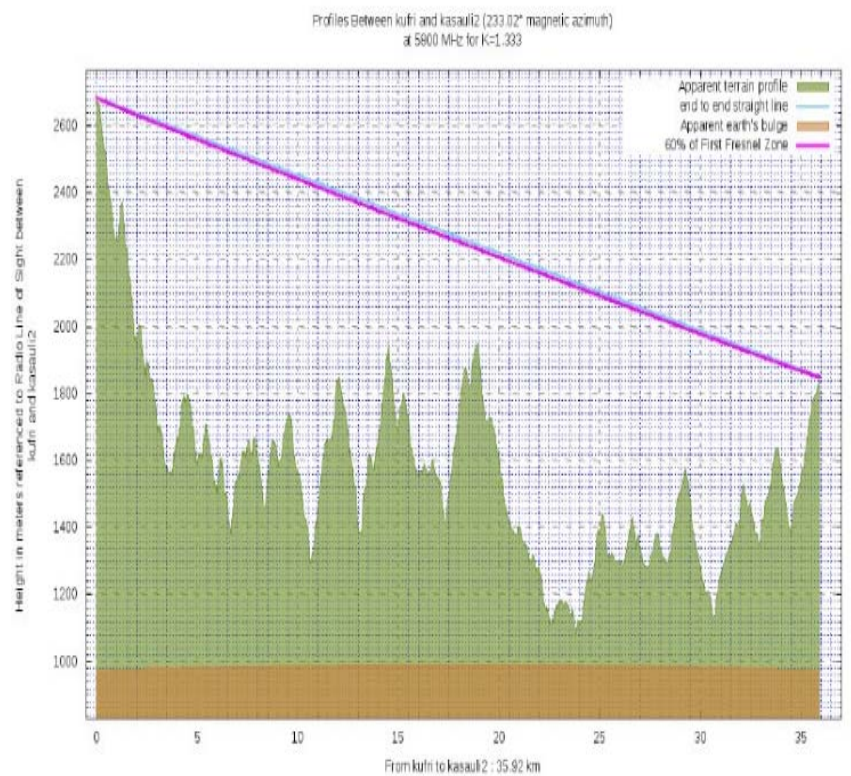

Figure 3 (e)Link 3. Kufri Shimla to Kasauli

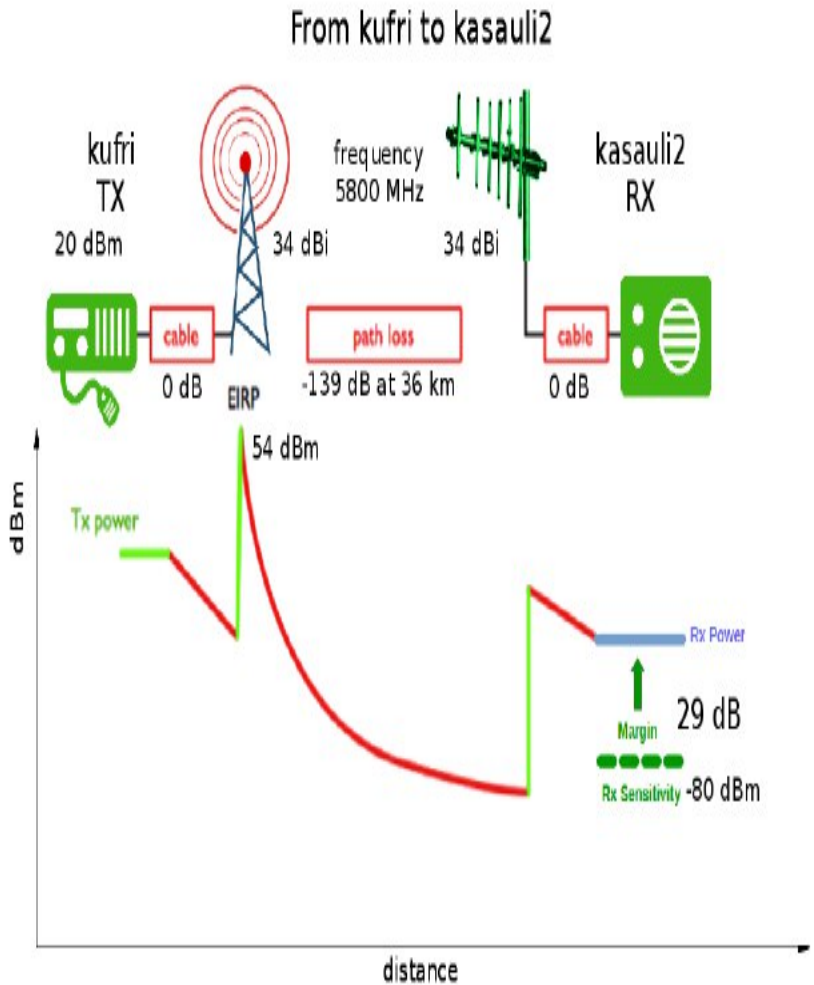

Figure 3 (f)Power vs distance on the Kufri- Kasauli link

These margins of 17,16 and $29 \mathrm{~dB}$ provide a quite reliable signal that will supportthe highest modulation schemes, affording transmission speeds in the megabit per second range.

\section{Robustness}

Because of the geographic locations of major earthquake (faults) in Himachal, falling under zone $\mathrm{V}$, the area of interest is vulnerable to seismic activity. For this reason we have envisioned a ring topology, which provides an alternate path to reach the destination in case of failure of one link. This is shown inFigure 4.

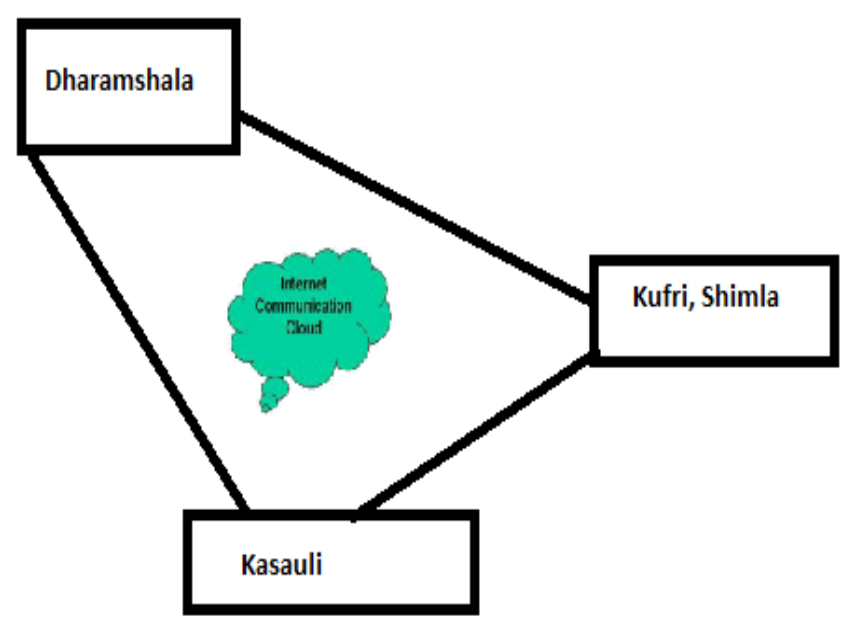

Figure 4: Ring Topology between selected sites

\section{Seismic Sensors and its connectivity with Radio}

Seismic Sensors would be placed in the seismic Zone V i.e Kangra/ Dharamshala. These would be connected as per the layout of EEW system given in figure 5: 
of India, for early earthquake monitoring would be quite effective.

Layout of Earthquake Early Warning System Using Seismic Sensors

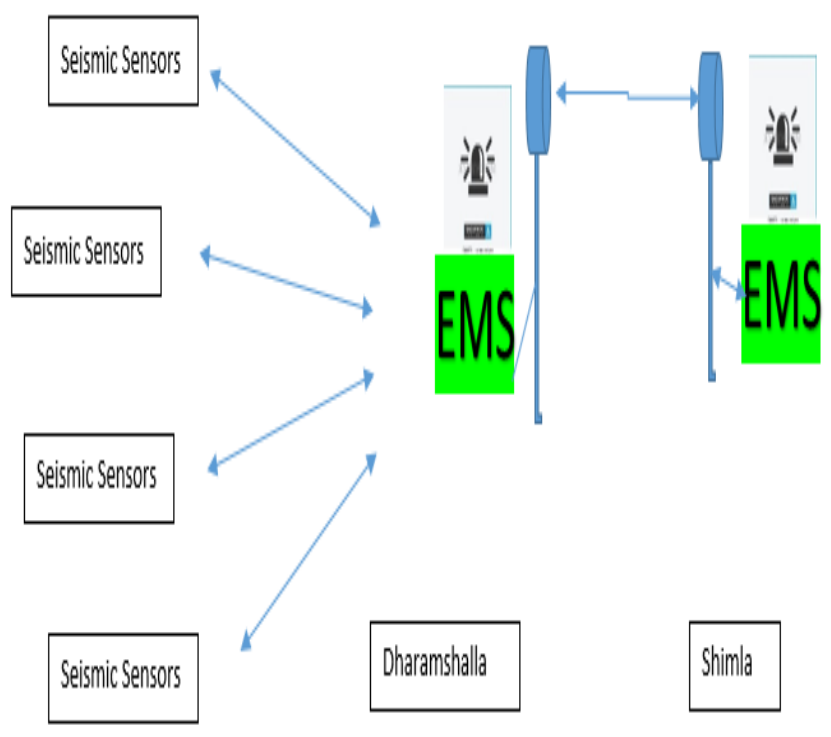

Figure 5 Layout of EEWS Using Seismic Sensors

Earthquake Monitoring System (EMS) will first sense $\mathrm{P}$ wave received from more than three seismic sensors and only then an alarm would be raised and an EEW signal would be sent to next station through radio based architecture for early warning system.

\section{CONCLUSION}

In the present paper, authors have presented an architecturaldesign set up for early earthquake monitoring and have assessed the effectiveness of using BotRf Telegramsimulation for establishing long distance Wi-Fi link. A dedicated communication ring connecting three locations within the state of Himachal Pradesh is presented in the ring topology having the advantage that can also be used to exchange other data besides the one pertaining to the earthquake, since the links will support a much higher data traffic and still offer very low latency, of the order of a few ms. Being a dedicated ring (not part of the commercial Internet), it remains unaffected by commercial traffic during and after an earthquake. emergency offices throughout the country.

On the basis of simulation results, it may be concluded that:

- Seismic Sensors/WSN may be integrated with these long distance Wi- Fi links. A functional architectural design to set up testbed in the remote location of western Himalayan Region
- The simulation for such long distancelinks prove its usefulness in monitoring the Early Earthquake Warning system and save lives in sensitive seismic zones of western Himalayan Region of India.

- To set up Long distance Wi-Fi network will be a major steps to improve the robustness of earthquake monitoring systems in this region as already mentioned that internet, cables may not work during earthquake. Only source of communications would be the radio link.

- A plan to include a study the feasibility of establishing a link with Nepal (seismic zone V) would be highly useful for early earth quakewarning system.

\section{REFERENCES:}

1. https://www.britannica.com/topic/Nepalearthquake-of-2015 assessed on 30th Jan 2018accessedon 30th Jan 2018

2. http://123himachal.com/dharamsala/links/1905.ht $m$ accessed on 30th Jan 2018

3. http://www.tribuneindia.com/2012/20120413/edit .htm accessed on 30th Jan 2018

4. httD://www.tribuneindia.com/news/himachal/ca lamities-no-lessons-learnt-state-still-illeauinped/540818.html accessed on 12 Feb 2018

5. http://www.cnet.com/news/new-wi-fi-distancerecord-382-kilometers

6. E. Pietrosemoli, M. Zennaro and C. Fonda, Low cost carrier independent telecommunications infrastructure, in proceedings of the 4th Global Information Infrastructure and Networking Symposium, Choroni, Venezuela, 2012.

7. C. Rey-Moreno et alt, A Telemedicine WiFi Network Optimized for Long Distance in the Amazonian Jungle of Peru, ExtremeCom'11, September 26, 2011

8. M. Zennaro. M. Rainone and E. Pietrosemoli.Radio Link Planning made easv with a Telegram Bot. in nroceedings of the $2 \mathrm{nd}$ EAI International Conference on Smart Obiects and Technologies for Social Good. November 30 - December 1, 2016, Venice, Italy.

9. https://telegram.orgaccessed January 8, 2018

10. httDs://earthauake.usgs.gov/research/earlywarn ing/ accessed on 30th Jan 2018

11. Marco Zennaro. Antoine Bagula and David Gascon. Planning and Denloving long distance Wireless Sensor Network: The integration of simulation and experimentation. ADHOCNOW LNCS 6288 nn 191-204, springerverlag Berlin Heidelberg 2010

12. B Raman B., Chebrolu, K, 2007. Experiences in using Wi-Fi for rural internet in India. IEEE communications Magazines Special issue on New 
Dhirendra Sharma et al, International Journal of Advanced Research in Computer Science, 9 (1), Jan-Feb 2018, 186-193

Directions in Networking Technologies in Emerging Economies (Jan 2007)

13. WirelessU,Wireless Networking in the developing world, Third edition. (2013), http://wndw.net
14. http://wireless.ictp.it/publications.html 